\title{
Enriched childhood experiences moderate age-related motor and cognitive decline
}

\author{
Megan J. Metzler ${ }^{1}$, Deborah M. Saucier ${ }^{1,2 \dagger}$ and Gerlinde A. Metz ${ }^{1 * \dagger}$ \\ ' Canadian Centre for Behavioural Neuroscience, University of Lethbridge, Lethbridge, AB, Canada \\ 2 The Dean of Science, University of Ontario Institute of Technology, Oshawa, ON, Canada
}

\author{
Edited by: \\ Melly S. Oitzl, Leiden University \\ Medical Center, Netherlands \\ Reviewed by: \\ Melly S. Oitzl, Leiden University \\ Medical Center, Netherlands \\ Robert J. Ellis, Beth Israel \\ Deaconess Medical Center, USA \\ *Correspondence: \\ Gerlinde A. Metz, Canadian Centre \\ for Behavioural Neuroscience, \\ University of Lethbridge, \\ 4401 University Drive, Lethbridge, \\ AB T1K 3M4, Canada. \\ e-mail: gerlinde.metz@uleth.ca \\ ${ }^{\dagger}$ These authors have contributed \\ equally to this work.
}

Aging is associated with deterioration of skilled manual movement. Specifically, aging corresponds with increased reaction time, greater movement duration, segmentation of movement, increased movement variability, and reduced ability to adapt to external forces and inhibit previously learned sequences. Moreover, it is thought that decreased lateralization of neural function in older adults may point to increased neural recruitment as a compensatory response to deterioration of key frontal and intra-hemispheric networks, particularly of callosal structures. However, factors that mediate age-related motor decline are not well understood. Here we show that music training in childhood is associated with reduced age-related decline of bimanual and unimanual motor skills in a MIDI keyboard motor learning task. Compared to older adults without music training, older adults with more than a year of music training demonstrated proficient bimanual and unimanual movement, evidenced by enhanced speed and decreased movement errors. Further, this group demonstrated significantly better implicit learning in the weather prediction task, a non-motor task. The performance of older adults with music training in those tasks was comparable to young adults. Older adults, however, displayed greater verbal ability compared to young adults irrespective of a past history of music training. Our results indicate that music training early in life may reduce age-associated decline of neural motor and cognitive networks.

Keywords: bimanual motor skill, motor coordination, weather prediction task, keyboard, piano, music training, implicit learning, verbal ability

\section{INTRODUCTION}

Aging impacts many critical aspects of movement and cognition. Aging is implicated in slower reaction times (Riecker et al., 2006; Poston et al., 2009) and slower execution of movement during standardized motor tests (Ruiz et al., 2007), drawing tasks (Lee et al., 2010), and reaching movements (Rossit and Harvey, 2008; Poston et al., 2009; Verrel et al., 2012). Older adults adjust and inhibit motor movements more slowly than their younger counterparts (Potter and Grealy, 2006; Sarlegna, 2006; Rossit and Harvey, 2008) including for finger sequences (Trewartha et al., 2009) and bimanual movements (Swinnen, 1998). Older adults also demonstrate greater variability of movement compared to young adults for tapping (Bangert et al., 2010), reaching (Cooke et al., 1989), and grip force in interacting with an object (Danion et al., 2007). Evidence suggests that older adults use different strategies across a range of movements (Ketcham et al., 2004; Cesqui et al., 2008). In addition, aging is commonly associated with a decline in episodic memory, verbal ability, and non-verbal reasoning (James et al., 2011; Pillai et al., 2011). Age-related cognitive decline also involves attention and visuoperceptual abilities (Ardila et al., 2000; Yochim et al., 2009), which in turn may affect motor skill learning.

Aging is also linked to disruption of neural pathways essential to skilled movement. In diffusion tensor fMRI, older adults show axonal shrinkage, demyelination, and even axonal loss in pericallosal and callosal pathways compared to their younger counterparts (Bennett et al., 2010). Evidence suggests that these neural changes contribute to age-related movement deterioration and result in altered patterns of neural activation. Reported changes in neural activation associated with aging include increased activation of ipsilateral M1 (Naccarato et al., 2006), sensorimotor (Riecker et al., 2006) and premotor cortices (Riecker et al., 2006; Rowe et al., 2006). Older adults also exhibit more local connectivity and reduced connectivity between distant motorrelated areas (Rowe et al., 2006). During bimanual movement, older adults show decreased lateralization (Przybyla et al., 2011) and additional areas of activation, such as the SMA, inferior parietal cortex, and dorsolateral prefrontal cortex, despite slower movement speed (Goble et al., 2010). Decreased lateralization of neural function in older adults may point to increased recruitment of neural resources as compensation for deterioration of frontal and key intra-hemispheric networks, particularly of callosal structures (Naccarato et al., 2006; Riecker et al., 2006; Rowe et al., 2006; Bangert et al., 2010; Bennett et al., 2010). However, factors that influence age-related motor deterioration were not clearly delineated.

The multimodal nature of music training has been shown to enhance motor skills and cognitive abilities alike (Haslinger et al., 2005; D'Ausilio et al., 2006; Forgeard et al., 2008; Moreno et al., 2011). The present study investigates the relationship between 
skilled motor, episodic (verbal) and implicit (weather prediction task) learning in young vs. older healthy subjects as a function of music training in childhood. Using a newly developed motor task, we show that early music training diminishes age-related decline of bi- and unimanual motor skills. Our results indicate that childhood experiences such as music training may have a protective effect on age-associated decline of neural motor networks.

\section{METHODS \\ SUBJECTS}

Twenty-seven young adults $(M=21.13, S D=2.53)$ and 29 older adults $(M=73.03$ years, $S D=9.59)$ participated in the study (Table 1). The group of young adults consisted of university-age students who participated in the study for credit in undergraduate courses through the Department of Psychology's Human Subject Pool. Older adults were recruited through a local senior center and word of mouth. Exclusion criteria included history of neurological or motor impairment and playing the piano in the past year. Four cases were excluded due to movement disorders resulting from neurological or orthopaedic conditions; one subject withdrew from the study. Ethics approval for the study was obtained from the University of Lethbridge Human Subject Committee.

\section{BEHAVIORAL TESTING}

After giving informed consent, hand dominance was determined via a questionnaire (Elias et al., 1998). Both left and right handed individuals were included in the study. Participants performed several movement sequences on a MIDI keyboard, a vocabulary test (Ekstrom et al., 1976) and the weather prediction task (Figure 1). The vocabulary test asked participants to choose synonyms of target words to assess advanced vocabulary and extended range vocabulary. The weather prediction task is a probability learning task and a measure of implicit learning that involves the basal ganglia dopamine system (Knowlton et al., 1994; Rieckmann and Bäckman, 2009). Using a computer program, participants were provided with sets of different shapes and asked to predict the outcome and indicate the strategy used to solve the task.

Participants performed symmetrical and asymmetrical movements comprising of the first five notes of $\mathrm{C}$ major standard and contrary motion scales, respectively (Figure 1). For symmetrical and asymmetrical movements and for movements with either the dominant and non-dominant hand alone the speed [sec/keystroke] and the errors [per eight clean trials] were analysed. Participants were further divided into groups that had received a year or more of music lessons $(\mathrm{M}+)$ or less than a year of music lessons $(\mathrm{M}-$ ) (26 participants, 11 older adults had received lessons; Table 1). Of those who had received music lessons in the past, older adults had on average 3.81 (1.78 SD) years of lessons, whereas younger adults had on average 2.40 (1.74 SD) years of lessons. Of the 26 participants who had taken music lessons, only 9 had taken piano lessons (Table 1). Regardless, in order to participate in the study, participants could not actively have played the piano within the past year. Further, participants had not taken music lessons since adolescence.

\section{STATISTICAL ANALYSIS}

Statistical analysis included Pearson's correlation coefficients and Fisher's $r$ to $z$-transformation and $z$-tests (Meng et al., 1992). Furthermore, post-hoc analyses (Bonferroni) were performed to determine group differences. One young $\mathrm{M}+$ subject was excluded from correlation analysis because the number of years of music training was not known. A $p$-value of $<0.05$ was chosen as the significance level.

\section{RESULTS \\ A HISTORY OF MUSIC LESSONS IS LINKED TO IMPROVED MANUAL MOTOR PERFORMANCE}

All analyses of bimanual and unimanual motor performance revealed an effect of past history of lessons and age group (Table 2; Figures 2A,B). Furthermore, for all variables, motor performance was negatively related to the number of years of music training in $\mathrm{M}+$ subjects (Table 3; Figure 3). Thus, longer music training was associated with better movement performance in both young $(n=15)$ and older $M+$ subjects $(n=11)$ as outlined in the following.

In movement speed with the bimanual components of the motor learning task, the years of music training were related to faster manual performance in both symmetrical (all $p$ 's $>$ 0.01 ) and asymmetrical conditions (all $r$ 's $<-0.43, p>0.05$ for young, $p>0.0) 1$ for older adults; see Table 3). The correlations became stronger in young adults when only $\mathrm{M}+$ subjects were included $(p<0.05)$, but weaker in older adults under the same conditions (all $r$ 's $<-0.57$ for young, all $r$ 's $<-0.40$ for older adults). Interestingly, post-hoc analyses (Bonferroni) indicated that $\mathrm{M}$ - older adults were significantly slower than any of the other three groups (Figure 2A). There were no significant differences among the other three groups. Exploratory analyses suggested that $\mathrm{M}$ - older adults performed the asymmetrical task with less speed $(M=0.95, S D=0.35$; compared to the next highest mean, $\mathrm{M}-$ young adults, at $M=0.53, S D=0.31$ or $\mathrm{M}+$ older adults, $M=0.38, S D=0.25$ ).

Table 1 | Summary of demographic data of the subjects.

\begin{tabular}{|c|c|c|c|c|c|c|}
\hline & Number of subjects & Age range & Mean age & Years of training (range) & Mean years of training & Piano experience \\
\hline Young $\mathrm{M}-$ & $12(8 \mathrm{M}, 4 \mathrm{~F})$ & 19-28 & 22.58 & 0 & 0 & 0 \\
\hline Young M+ & $15(6 \mathrm{M}, 9 \mathrm{~F})$ & $18-26$ & 20.16 & $1-6$ & 2.40 & 2 \\
\hline Older M- & $18(8 \mathrm{M}, 10 \mathrm{~F})$ & 59-95 & 74.67 & 0 & 0 & 0 \\
\hline Older M+ & $11(5 \mathrm{M}, 6 \mathrm{~F})$ & $55-81$ & 70.36 & $1-10$ & 3.81 & 7 \\
\hline
\end{tabular}

M, male; F, female. 


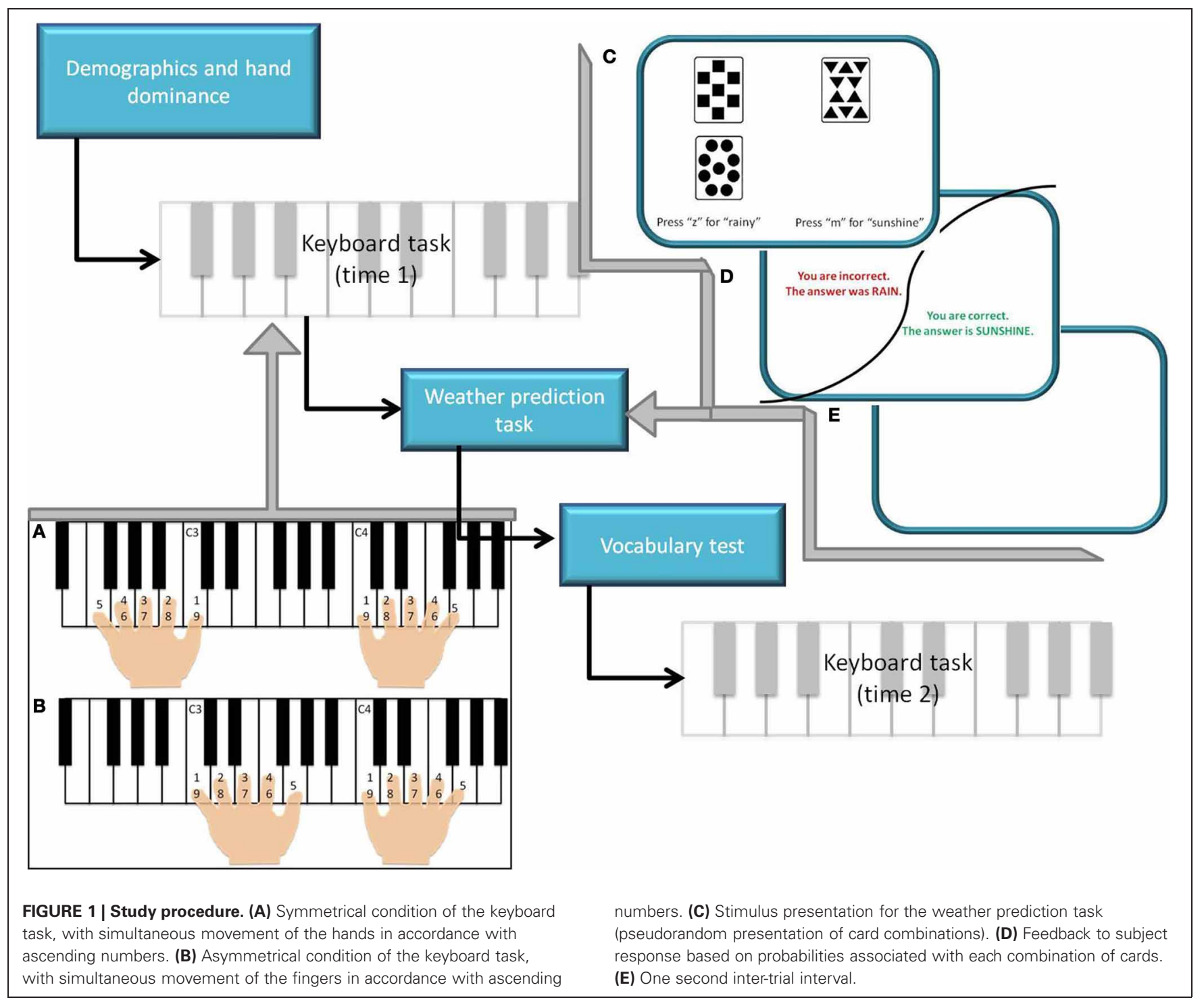

Table 2 | Mean scores ( \pm SDs) on the three tasks for older and young adults with and without music training (M-: no history of music lessons; $\mathrm{M}+$ : positive history of music lessons).

\begin{tabular}{|c|c|c|c|c|c|c|}
\hline & & $\frac{\text { Vocabulary }}{\text { Correct* }^{*}}$ & \multicolumn{2}{|c|}{ Motor learning task } & \multicolumn{2}{|c|}{ Weather prediction task } \\
\hline & $\mathrm{M}+$ & $10.200(3.166)$ & $0.337(0.187)$ & $4.436(3.803)$ & $1713.264(416.247)$ & $58.021(12.261)$ \\
\hline Younger adults & $M-$ & $4.580(2.001)$ & $0.425(0.198)$ & 5.333 (3.109) & 1332.979 (263.386) & $60.686(7.144)$ \\
\hline
\end{tabular}

Bold text indicates that the group performed significantly worse than the other 3 groups. ${ }^{*}$ Indicates a main effect of age group, $p<0.05 .{ }^{* *}$ Indicates an interaction between age group and history of lessons, $p<0.05$.

Similarly, a past history of music lessons was associated with improved performance in a unimanual task. The speed of performance with the non-dominant and the dominant hand became faster in young and older adults with more years of music training ( $r$ 's $<-0.39$ and $p$ 's $>0.05$ for young; $r$ 's $<-0.61$ and $p$ 's $<0.001$ for older adults; see Table 3 ). This association became stronger in young adults and weaker in older adults when only M+ subjects were included (all $p$ 's $<0.05$; Table 3 ). 

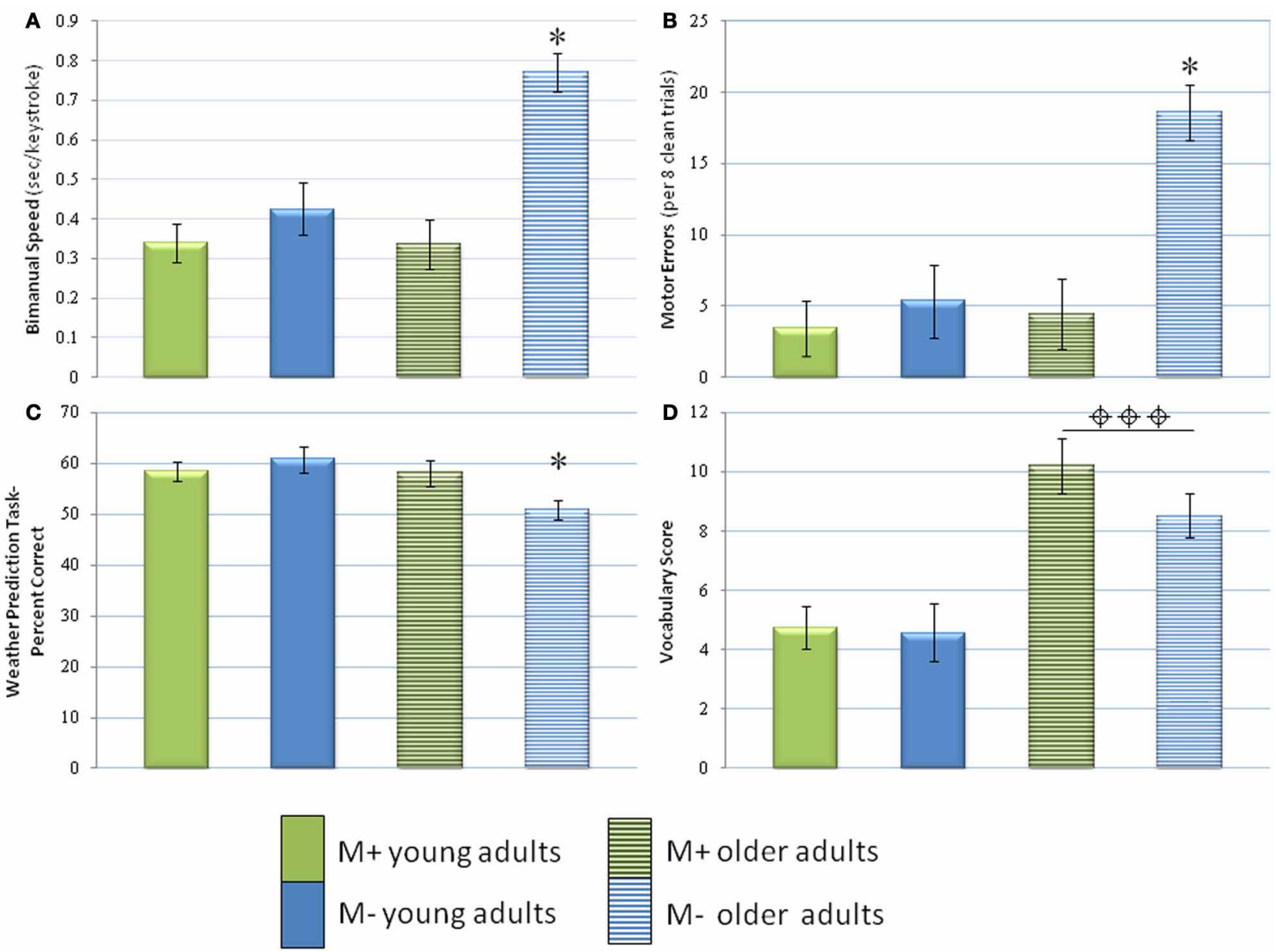

\section{$\mathrm{M}+$ older adults \\ M- older adults}

FIGURE 2 | Performance of $\mathbf{M}$ - and $\mathbf{M}+$ older and young adults. Results of the bimanual task (A, speed; B, errors), weather prediction task (C, percent correct), and vocabulary task (D, score) are displayed. For measures with which there was an interaction of age and history of music lessons, ${ }^{*}$ denotes the group that performed significantly worse than the other groups. For measures with which there was only an effect of age, $\phi \phi$ denotes the age group that performed significantly better. Note that music training preserved bimanual performance and implicit learning in the weather prediction task.

* indicates $p<0.05, \phi \phi$ indicates $p<0.001$. Bars represent the means and error bars represent the standard deviation.

Table 3 | Summary of correlations of years of music training with manual motor performance and cognitive performance among age groups $(\mathrm{M}-$ and $\mathrm{M}+$ ) and $\mathrm{M}+$ participants.

\begin{tabular}{|c|c|c|c|c|}
\hline Years of music training & $r$ Young $(\mathrm{M}-$ and $\mathrm{M}+)$ & $r$ Young $(\mathrm{M}+)$ & $r$ Older $(\mathrm{M}-$ and $\mathrm{M}+)$ & $r$ Older $(\mathrm{M}+)$ \\
\hline Asymmetrical speed & $-0.431 *$ & $-0.573^{*}$ & $-0.626 * * *$ & -0.404 \\
\hline Dominant speed & $-0.443^{*}$ & $-0.603^{*}$ & $-0.606 * * *$ & $-0.661^{*}$ \\
\hline Symmetrical errors & $-0.396^{*}$ & -0.484 & $-0.382^{*}$ & -0.359 \\
\hline Dominant errors & -0.187 & -0.297 & $-0.434^{*}$ & -0.268 \\
\hline Weather prediction \% & 0.120 & 0.333 & 0.077 & -0.486 \\
\hline Weather prediction time & 0.102 & 0.111 & 0.202 & 0.312 \\
\hline Vocabulary & -0.087 & -0.014 & 0.094 & -0.287 \\
\hline
\end{tabular}

Correlation coefficients (r-values) are provided and significance levels are noted with asterisks: ${ }^{*} p<0.05 ;{ }^{* *} p<0.01 ;{ }^{* * *} p<0.001$. 

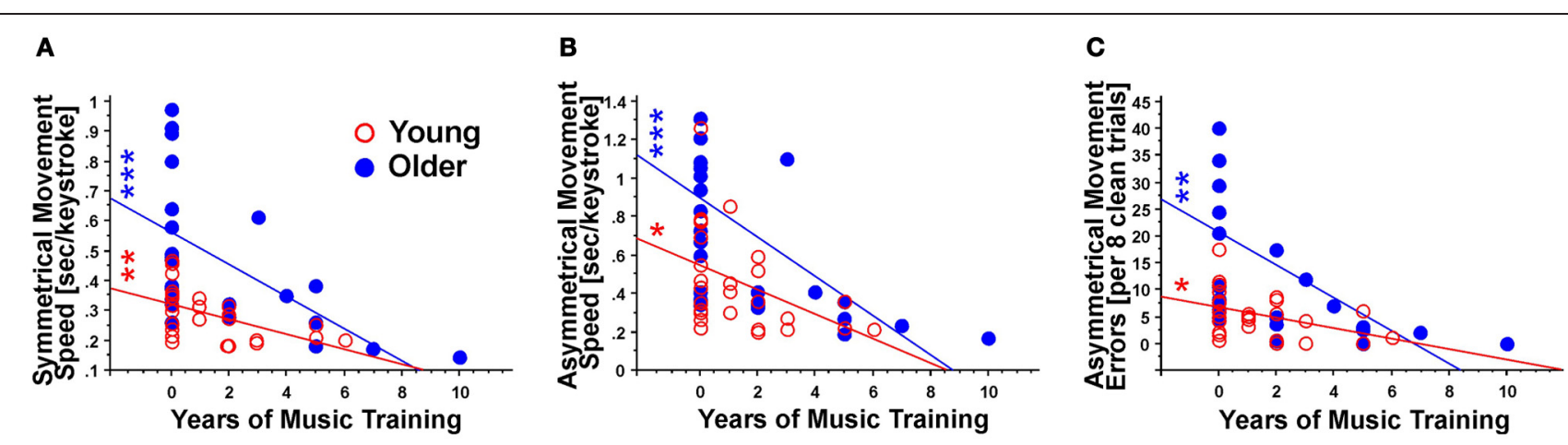

FIGURE 3 | Correlation analysis of the years of music training with motor performance in terms of (A) symmetrical movement speed; (B) asymmetrical movement speed; and (C), asymmetrical movement errors. Note the overall negative correlation between the variables, indicating that longer music training is related to better motor performance. These correlations were stronger for older individuals than for younger ones. ${ }^{*}$ Indicates $p<0.05$; **Indicates $p<0.01$; *** Indicates $p<0.001$
The years of music performance were strongly related to motor performance independently of the type of instrument played (see Table 4). In $\mathrm{M}+$ individuals who had taken piano lessons, the associations were stronger among older adults (e.g., dominant speed $r=-0.77, p<0.05)$ than among all age groups combined (dominant speed $r=-0.471, p<0.05$ ). Furthermore, performance in the unimanual task revealed that $\mathrm{M}-$ older adults were much slower with their dominant and non-dominant hands than any other group (all p's $<0.001$; dominant hand: $M-$ older adults $M=0.37, S D=0.11, M+$ older adults $M=0.24$, $S D=0.07$; non-dominant hand: $M-$ older adults $M=0.42$, $S D=0.11$ vs. $M+$ older adults $M=0.26, S D=0.078) . M-$ older adults moved their dominant hand significantly faster than their non-dominant hand $(p<0.001)$. The number of errors made with their dominant and non-dominant hands was also higher for $\mathrm{M}$ - older adults compared to any other group (all p's $<0.01$; dominant hand: $M-$ older adults $M=4.26, S D=$ 2.87, $M+$ older adults $M=1.63, S D=1.16$; non-dominant hand: $M-$ older adults $M=5.28, S D=6.99$ vs. $M+$ older adults $M=1.73, S D=1.66)$.

The analysis of movement errors revealed again a negative association between the past history of music lessons and performance in both bimanual and unimanual conditions (Tables 2 and 3). This association became significant for the age effect when including both $\mathrm{M}-$ and $\mathrm{M}+$ subjects ( $r$ 's $<0.38$, $p$ 's $<0.05$ ). Thus, among all participants music experience in childhood was associated with lower error rates in the symmetrical and asymmetrical conditions of the bimanual task. Furthermore, older adults with music training displayed reduced error rates in the dominant hand $(r=-0.43, p<0.05$; Table 3). Post-hoc analyses (Bonferroni) indicated that $\mathrm{M}-$ older adults made significantly more errors than any of the other three groups $(p<0.05$; Figure 2B). There were no other significant differences among the other three groups.

\section{MUSIC TRAINING IS ASSOCIATED WITH ENHANCED IMPLICIT LEARNING ABILITY}

For the weather prediction task, correlational analysis revealed an overall positive relationship between past history of lessons
Table 4 | Summary of correlations among the years of music training in $\mathrm{M}+$ subjects concerning the past experience playing piano vs. playing other instruments.

\begin{tabular}{lll}
\hline $\begin{array}{l}\text { Years of music } \\
\text { training }\end{array}$ & $\begin{array}{l}\boldsymbol{r} \text { Young and older } \\
\text { with piano lessons }\end{array}$ & $\begin{array}{l}\boldsymbol{r} \text { Young and older } \\
\text { without piano lessons }\end{array}$ \\
\hline Symmetrical speed & -0.382 & $-0.459^{*}$ \\
Asymmetrical speed & -0.405 & $-0.454^{*}$ \\
Non-dominant speed & $-0.473^{*}$ & $-0.480^{*}$ \\
Dominant speed & $-0.471^{*}$ & $-0.479^{*}$ \\
Symmetrical errors & -0.271 & -0.248 \\
Asymmetrical errors & -0.281 & -0.429 \\
Non-dominant errors & -0.044 & -0.114 \\
Dominant errors & -0.279 & -0.160
\end{tabular}

Correlation coefficients ( $r$-values) are provided and significance levels are noted with asterisks: ${ }^{*} p<0.05$.

and the percentage of correct responses (all r's $>0.09$ ). $Z$-scores revealed no significance. Notably, post-hoc analyses (Bonferroni) indicated that $\mathrm{M}$ - older adults performed significantly more poorly than the other three groups (all $p$ 's $<0.05$; Figure 2C). No other significant differences were found.

In terms of the time needed to complete the weather prediction task, correlations revealed a positive, but no significant relationship. Older adults took more time to complete the trials correctly than young adults $(p<0.01$; older adults, $M=1626.44, S D=$ 447.46; younger adults, $M=1317.32, S D=379.84$; Table 2).

Two-Tailed tests revealed a significant negative relationship between the percent correct in the weather prediction task and symmetrical movement speed $(p<0.01)$, asymmetrical movement speed $(p<0.01)$, and asymmetrical error $(p<0.05)$. Furthermore, the reaction time in the weather prediction task was positively correlated with asymmetrical movement speed $(p<0.001)$, symmetrical movement error $(p<0.05)$, and asymmetrical movement error $(p<0.01)$.

In the vocabulary task, performance was positively related to the past history of music lessons $(r=0.08)$ in older adults, 
and negatively in younger adults, although the correlation was not significant. Performance in the vocabulary task was also positively related to reaction time in the weather prediction task among all ages and groups combined $(p<0.05, r=0.26)$, but not to motor performance. Importantly, older adults $(M=9.17$, $S D=3.74)$ performed significantly better than young adults in the vocabulary task ( $p<0.001 ; M=4.69, S D=2.23$; Table 2, Figure 2D).

\section{DISCUSSION}

The present data show that in the absence of differences in bimanual performance among $\mathrm{M}-$ and $\mathrm{M}+$ young adults, $\mathrm{M}+$ older adults performed significantly better than $\mathrm{M}$ - older adults in the keyboard task. This change occurred regardless of the instrument learned and was not influenced by previous experience playing the piano. The absence of a significant difference in performance between $\mathrm{M}+$ older adults and young adults suggests that the protective effect of beneficial childhood experiences, including music training, is durable and potent. Remarkably, $\mathrm{M}-$ older adults also performed significantly more poorly than other groups on a measure of implicit learning, the weather prediction task, in terms of percentage of correct responses. Consequently, these differences cannot solely be attributed to preservation of peripheral motor systems as a result of music training, but must involve central neural systems. Nevertheless, the results of the vocabulary test do not point to innate differences between $\mathrm{M}-$ and $\mathrm{M}+$ older adults, and confirm aging-related improvement in semantic knowledge (Verhaeghen, 2003). Consequently, our research suggests that music training selectively alters neural systems implicated in motor learning in the absence of global neurological change.

The present results are in line with studies suggesting a link between motor and cognitive processing in older adults. For example, older adults exhibit temporal declines of bimanual circle drawing and simultaneous tapping (Bangert et al., 2010). Interestingly, lower executive function correlated with asynchronous inter-manual timing deficits, and better performance of the most difficult bimanual circling task was associated with better working memory for older adults (Bangert et al., 2010). This led to the postulation that for the older adults, executive and working memory functions are engaged for difficult tasks (Bangert et al., 2010).

The weather prediction task may provide a means of investigating the integrity of neural structures necessary for manual movement. Further, the results also suggest that music training in childhood may reduce the global decline of central dopamine function normally associated with aging (Rieckmann and Bäckman, 2009). While the weather prediction task may reflect the integrity of the basal ganglia dopamine system (Moody et al., 2004), recent studies have challenged the notion of impaired performance associated with deterioration of the neostriatum (Wilkinson et al., 2008; Jahanshahi et al., 2010). Alternatively, it may be argued that performance of a bimanual keyboard task and the weather prediction task rely on shared patterns of connectivity that are strengthened by music training. The rather weak correlation between performance in these tasks argues for the involvement of both shared and unshared neuronal substrates.
While the present data suggest a positive influence of early music training on age-related functional decline, other childhood experiences may contribute to these outcomes. An environment enriched with music lessons may be associated with other exposures that support behavioral, physiological, and neurological development, such as tactile stimulation (Sharp et al., 2012), nutritional or social variables (Forns et al., 2012). Furthermore, lifetime leisure activities (James et al., 2011; Pillai et al., 2011; Gow et al., 2012), stress (Segovia et al., 2009; Merrett et al., 2010), physical activity (Buchman et al., 2012), social activity (Buchman et al., 2009), and education (Ardila et al., 2000; Van Gerven et al., 2012) may individually or synergistically affect the rate of age-related functional decline. Accordingly, animal studies have shown beneficial effects of environmental enrichment on skilled motor function (Jadavji et al., 2006; Jadavji and Metz, 2009; Knieling et al., 2009), age-related memory decline and neuronal plasticity (Leal-Galicia et al., 2008; Segovia et al., 2009). Notably, enrichment results in increased myelination of aged rat corpus callosum (Zhao et al., 2012), a structure central to bimanual coordination and music performance (Schlaug et al., 1995).

Prior research points to a neural mechanism which may underpin our findings. It is established that music training results in activation of an extensive network that includes auditory and sensorimotor networks (Bangert and Altenmüller, 2003; Haslinger et al., 2005; Bangert et al., 2006; D’Ausilio et al., 2006). Whether music training prevents age-related deterioration of the underlying anatomical structures and pathways or simply provides an effective means of compensation remains unclear at this point. Ultimately, music training results in macrostructural changes to the brain, specifically of the primary motor and somatosensory cortices, inferior temporal gyri, anterior corpus callosum, and cerebellar cortex (Elbert et al., 1995; Schlaug et al., 1995; Gaser and Schlaug, 2003; Gentner et al., 2010). Hence, music training results in differential augmentation of key areas of the motor network, including callosal structures. Accordingly, symmetrical movement is shown to rely on efficient input from the dominant to the non-dominant hemisphere for movement (Maki et al., 2008; Walsh et al., 2008). Presumably, strengthening of neural connections between these key areas likely plays a vital role in preservation of manual motor learning and performance in the long term. The present results suggest that music training early in life may attenuate the decline of neural motor and cognitive networks associated with advanced age.

\section{AUTHOR CONTRIBUTIONS}

Megan J. Metzler, Deborah M. Saucier, and Gerlinde A. Metz designed the study. Megan J. Metzler wrote computer code for data extraction and collection, recruited subjects and collected the data. Megan J. Metzler and Gerlinde A. Metz wrote the manuscript and created figures. Deborah M. Saucier and Gerlinde A. Metz completed the statistical analysis, wrote the results, and provided equipment and software.

\section{ACKNOWLEDGMENTS}

The authors wish to thank Dr. Robert Sutherland for comments on the manuscript, Dr. Matthew Tata, Brian Allen, and Jarrod Dowdall for assistance with writing code and Dr. Amanda Price 
for sharing components of software for the weather prediction task. The authors are grateful to the Lethbridge Senior Citizens Organization for providing space and assistance with recruitment. This work was supported by the Natural Sciences and Engineering Research Council of Canada (Deborah M. Saucier;

\section{REFERENCES}

Ardila, A., Ostrosky-Solis, F., Rosselli, M., and Gómez, C. (2000). Agerelated cognitive decline during normal aging: the complex effect of education. Arch. Clin. Neuropsychol. $15,495-513$.

Bangert, M., and Altenmüller, E. O. (2003). Mapping perception to action in piano practice: a longitudinal DC-EEG study. BMC Neurosci. 4:26. doi: 10.1186/ 1471-2202-4-26

Bangert, M., Peschel, T., Schlaug, G., Rotte, M., Drescher, D., Hinrichs, H., et al. (2006). Shared networks for auditory and motor processing in professional pianists: evidence from fMRI conjunction. Neuroimage 30, 917-926.

Bangert, A. S., Reuter-Lorenz, P. A., Walsh, C. M., Schachter, A. B., and Seidler, R. D. (2010). Bimanual coordination and aging: neurobehavioral implications. Neuropsychologia 48, 1165-1170.

Bennett, I. J., Madden, D. J., Vaidya, C. J., Howard, D. V., and Howard, J. H. (2010). Age-related differences in multiple measures of white matter integrity: a diffusion tensor imaging study of healthy aging. Hum. Brain Mapp. 31, 378-390.

Buchman, A. S., Boyle, P. A., Wilson, R. S., Fleischman, D. A., Leurgans, S., and Bennett, D. A. (2009). Association between late-life social activity and motor decline in older adults. Arch. Intern. Med. 169, 1139-1146.

Buchman, A. S., Boyle, P. A., Yu, L., Shah, R. C., Wilson, R. S., and Bennett, D. A. (2012). Total daily physical activity and the risk of $\mathrm{AD}$ and cognitive decline in older adults. Neurology 278, 1323-1329.

Cesqui, B., Macrì, G., Dario, P., and Micera, S. (2008). Characterization of age-related modifications of upper limb motor control strategies in a new dynamic environment. J. Neuroeng. Rehabil. 5:31. doi: 10.1186/1743-0003-5-31

Cooke, J. D., Brown, S. H., and Cunningham, D. A. (1989). Kinematics of arm movements in elderly humans. Neurobiol. Aging $10,159-165$.

Danion, F., Descoins, M., and Bootsma, R. J. (2007). Aging affects the predictive control of grip force during object manipulation. Exp. Brain Res. 180, 123-137.

D'Ausilio, A., Altenmüller, E., Olivetti Belardinelli, M., and Lotze, M. (2006). Cross-modal plasticity of the motor cortex while listening to a rehearsed musical piece. Eur. J. Neurosci. 24, 955-958.

Ekstrom, R. B., French, J. W., and Harman, H. H. (1976). Manual for Kit of Factor Referenced Cognitive Tests. Princeton, NJ: Educational Testing Service.

Elbert, T., Pantev, C., Wienbruch, C., Rockstroh, B., and Taub, E. (1995). Increased cortical representation of the fingers of the left hand in string players. Science 270, 305-307.

Elias, L. J., Bryden, M. P., and BulmanFleming, M. B. (1998). Footedness is a better predictor than is handedness of emotional lateralization. Neuropsychologia 36, 37-43.

Forgeard, M., Winner, E., Norton, A., and Schlaug, G. (2008). Practicing a musical instrument in childhood is associated with enhanced verbal ability and nonverbal reasoning. PLoS ONE 3:e3566. doi: 10.1371/journal.pone.0003566

Forns, J., Torrent, M., Garcia-Esteban, R., Cáceres, A., Pilar Gomila, M., Martinez, D., et al. (2012). Longitudinal association between early life socio-environmental factors and attention function at the age 11 years. Environ. Res. 117, 54-59.

Gaser, C., and Schlaug, G. (2003). Brain structures differ between musicians and non-musicians. J. Neurosci. 23, 9240-9245.

Gentner, R., Gorges, S., Weise, D., aufm Kampe, K., Buttmann, M., and Classen, J. (2010). Encoding of motor skill in the corticomuscular system of musicians. Curr. Biol. 20, 1869-1874.

Goble, D. J., Coxon, J. P., Van Impe, A., De Vos, J., Wenderoth, N., and Swinnen, S. P. (2010). The neural control of bimanual movements in the elderly: brain regions exhibiting age-related increases in activity, frequency-induced neural modulation, and task-specific compensatory recruitment. Hum. Brain Mapp. 31, 1281-1295.

Gow, A. J., Mortensen, E. L., and Avlund, K. (2012). Activity

Gerlinde A. Metz), Canada Foundation for Innovation (Deborah M. Saucier), Alberta Innovates-Health Solutions (Gerlinde A. Metz), and the Canada Research Chairs Program (Deborah M. Saucier). Megan J. Metzler received a Keith and Hope Ferguson Memorial Scholarship.

participation and cognitive aging from age 50 to 80 in the glostrup 1914 cohort. J. Am. Geriatr. Soc. 60 1831-1838.

Haslinger, B., Erhard, P., Altenmüller, E., Schroeder, U., Boecker, H., and Ceballos-Baumann, A. O. (2005) Transmodal sensorimotor networks during action observation in professional pianists. J. Cogn. Neurosci. 17, 282-293.

Jadavji, N. M., Kolb, B., and Metz, G. A. (2006). Enriched environment improves motor function in intact and unilateral dopamine-depleted rats. Neuroscience 140, 1127-1138.

Jadavji, N. M., and Metz, G. A. (2009). Both pre- and post-lesion experiential therapy is beneficial in 6-hydroxydopamine dopaminedepleted female rats. Neuroscience 158, 373-386.

Jahanshahi, M., Wilkinson, L., Gahir, H., Dharmarinda, A., and Lagnado, D. A. (2010). Medication impairs probabilistic classification learning in Parkinson's disease. Neuropsychologia 48, 1096-1103.

James, B. D., Wilson, R. S., Barnes, L. L. and Bennett, D. A. (2011). Late-life social activity and cognitive decline in old age. J. Int. Neuropsychol. Soc 17, 998-1005.

Ketcham, C. J., Dounskaia, N. V., and Stelmach, G. E. (2004). Age-related differences in the control of multijoint movements. Motor Control 8, 422-436.

Knieling, M., Metz, G. A., AntonowSchlorke, I., and Witte, O. W. (2009). Enriched environment promotes efficiency of compensatory movements after cerebral ischemia in rats. Neuroscience 163, 759-769.

Knowlton, B. J., Squire, L. R., and Gluck, M. A. (1994). Probabilistic classification learning in amnesia. Learn. Mem. 1, 106-120.

Leal-Galicia, P., Castañeda-Bueno, M., Quiroz-Baez, R., and Arias, C. (2008). Long-term exposure to environmental enrichment since youth prevents recognition memory decline and increases synaptic plasticity markers in aging. Neurobiol. Learn. Mem. 90, 511-518.

Lee, D. Y., Fletcher, E., Martinez, O., Zozulya, N., Kim, J., Tran, J. et al. (2010). Vascular and degenerative processes differentially affect regional interhemispheric connections in normal aging, mild cognitive impairment, and Alzheimer disease. Stroke 41, 1791-1797.

Maki, Y., Wong, K. F., Sugiura, M., Ozaki, T., and Sadato, N. (2008). Asymmetric control mechanisms of bimanual coordination: an application of directed connectivity analysis to kinematic and functional MRI data. Neuroimage 42, 1295-1304.

Meng, X., Rosenthal, R., and Rubin, D. B. (1992). Comparing correlated correlation coefficients. Psychol. Bull. 111, 172-175.

Merrett, D. L., Kirkland, S. W., and Metz, G. A. (2010). Synergistic effects of age and stress in a rodent model of stroke. Behav. Brain Res. 214, 55-59.

Moody, T. D., Bookheimer, S. Y., Vanek, Z., and Knowlton, B. J. (2004). An implicit learning task activates medial temporal lobe in patients with Parkinson's disease. Behav. Neurosci. 118, 438-442.

Moreno, S., Bialystok, E., Barac, R., Schellenberg, E. G., Cepeda, N J., and Chau, T. (2011). Shortterm music training enhances verbal intelligence and executive function. Psychol. Sci. 22, 1425-1433.

Naccarato, M., Calautti, C., Jones, P. S., Day, D. J., Carpenter, T. A., and Baron, J. C. (2006). Does healthy aging affect the hemispheric activation balance during paced index-to-thumb opposition task? An fMRI study. Neuroimage 32, 1250-1256.

Pillai, J. A., Hall, C. B., Dickson, D. W., Buschke, H., Lipton, R. B., and Verghese, J. (2011). Association of crossword puzzle participation with memory decline in persons who develop dementia. J. Int Neuropsychol. Soc. 17, 1006-1013.

Poston, B., Van Gemmert, A. W. A. Barduson, B., and Stelmach, G. E. (2009). Movement structure in young and elderly adults during goal-directed movements of the left and right arm. Brain Cogn. 69, 30-38.

Potter, L. M., and Grealy, M. A. (2006). Aging and inhibitory errors on a motor shift of set task. Exp. Brain Res. 171, 56-66.

Przybyla, A., Haaland, K. Y., Bagesteiro, L. B., and Sainburg, R. L. (2011). 
Motor asymmetry reduction in older adults. Neurosci. Lett. 489, 99-104.

Riecker, A., Gröschel, K., Ackermann, H., Steinbrink, C., Witte, O., and Kastrup, A. (2006). Functional significance of age-related differences in motor activation patterns. Neuroimage 32, 1345-1354.

Rieckmann, A., and Bäckman, L. (2009). Implicit learning in aging: extant patterns and new directions. Neuropsychol. Rev. 19, 490-503.

Rossit, S., and Harvey, M. (2008). Age-related differences in corrected and inhibited pointing movements. Exp. Brain Res. 185, 1-10.

Rowe, J. B., Siebner, H., Filipovic, S. R., Cordivari, C., Gerschlager, W., Rothwell, J., et al. (2006). Aging is associated with contrasting changes in local and distant cortical connectivity in the human motor system. Neuroimage 32, 747-760.

Ruiz, P. J. G., Bernardos, V. S., Bartolomé, M., and Torres, A. G. (2007). Capit timed tests quantify age-related motor decline in normal subjects. J. Neurol. Sci. 260, 283-285.

Sarlegna, F. R. (2006). Impairment of online control of reaching movements with aging: a doublestep study. Neurosci. Lett. 403, 309-314.

Schlaug, G., Jäncke, L., Huang, Y., Staiger, J. F., and Steinmetz, H. (1995). Increased corpus callosum size in musicians. Neuropsychologia 33, 1047-1055.

Segovia, G., del Arco, A., and Mora, F. (2009). Environmental enrichment, prefrontal cortex, stress, and aging of the brain. J. Neural Transm. 116, 1007-1016.

Sharp, H., Pickles, A., Meaney, M., Marshall, K., Tibu, F., and Hill, J. (2012). Frequency of infant stroking reported by mothers moderates the effect of prenatal depression on infant behavioural and physiological outcomes. PLoS ONE 7:e45446. doi: 10.1371/journal.pone.0045446

Swinnen, S. P. (1998). Age-related deficits in motor learning and differences in feedback processing during the production of a bimanual coordination pattern. Cogn. Neuropsychol. 15, 439-466.

Trewartha, K. M., Endo, A., Li, K. Z. H., and Penhune, V. B. (2009). Examining prepotent response suppression in aging: a kinematic analysis. Psychol. Aging 24, 450-461.
Van Gerven, P. W., Van Boxtel, M. P., Ausems, E. E., Bekers, O., and Jolles, J. (2012). Do apolipoprotein E genotype and educational attainment predict the rate of cognitive decline in normal aging? A 12-year follow-up of the Maastricht Aging Study. Neuropsychology 26, 459-472.

Verhaeghen, P. (2003). Aging and vocabulary scores: a meta-analysis. Psychol. Aging 18, 332-339.

Verrel, J., Lövdén, M., and Lindenberger, U. (2012). Normal aging reduces motor synergies in manual pointing. Neurobiol. Aging 33, 200.e1-200.e10.

Walsh, R. R., Small, S. L., Chen, E. E. and Solodkin, A. (2008). Network activation during bimanual movements in humans. Neuroimage 43 , 540-553.

Wilkinson, L., Lagnado, D. A., Quallo, M., and Jahanshahi, M. (2008). The effect of feedback on nonmotor probabilistic classification learning in Parkinson's disease. Neuropsychologia 46, 2683-2695.

Yochim, B. P., Kane, K. D., and Mueller A. E. (2009). Naming test of the neuropsychological assessment battery: convergent and discriminant validity. Arch. Clin. Neuropsychol. 24, 575-583.
Zhao, Y. Y., Shi, X. Y., Qiu, X., Lu, W., Yang, S., Li, C., et al. (2012). Enriched environment increases the myelinated nerve fibers of aged rat corpus callosum. Anat. Rec. (Hoboken) 295, 999-1005.

Conflict of Interest Statement: The authors declare that the research was conducted in the absence of any commercial or financial relationships that could be construed as a potential conflict of interest.

Received: 20 August 2012; paper pending published: 17 September 2012; accepted: 31 January 2013; published online: 18 February 2013.

Citation: Metzler MJ, Saucier DM and Metz GA (2013) Enriched childhood experiences moderate age-related motor and cognitive decline. Front. Behav. Neurosci. 7:1. doi: 10.3389/fnbeh. 2013.00001

Copyright (๑) 2013 Metzler, Saucier and Metz. This is an open-access article distributed under the terms of the Creative Commons Attribution License, which permits use, distribution and reproduction in other forums, provided the original authors and source are credited and subject to any copyright notices concerning any third-party graphics etc. 